\section{Commentary: To transplant or to support with a ventricular assist device? Trying to uncover why differences in rates exist}

Vakhtang Tchantchaleishvili, MD, and John W. C. Entwistle, MD, PhD

The article in this issue of the Journal by Bourque and coauthors ${ }^{1}$ is the most granular population-level study to date to look at geographic and racial discrepancies in the use of durable mechanical circulatory support devices (MCSDs). Although the mechanisms generating these disparities remain unclear, there is variability in the rates of MCSD implantation by United Network for Organ Sharing (UNOS) region and race. In 7 of the 11 regions, the relative rate of growth in MCSD usage was greater in minorities than in whites.

Changes in the rate of heart transplantation in each region were seen with time; however, except in region 4, rates of heart transplantation for whites and minorities changed relatively little, as shown in the article's Figures 3 and $4 .^{1}$ This is in contrast to durable MCSD usage, for which rates increased in all regions and the changes were generally much larger than changes in heart transplantation. The approval of newer generation devices with markedly better outcomes than previous options probably underlies this increase.

It is thought provoking that there is a higher rate of MCSD usage in minorities, and a higher relative rate of growth in MCSD usage in minorities in most regions. This increase could be from one or several causes: higher incidence of heart failure in minorities ${ }^{2}$; improved recognition of treatment options and improved access to MCSD; greater barriers to access heart transplantation ${ }^{3}$; and greater bias in offering advanced health care to minorities. ${ }^{4}$

\footnotetext{
From the Division of Cardiac Surgery, Department of Surgery, Thomas Jefferson University, Philadelphia, $\mathrm{Pa}$.

No funding was provided for this article.

Disclosures: Authors have nothing to disclose with regard to commercial support.

Received for publication Oct 25, 2019; revisions received Oct 25, 2019; accepted for publication Oct 25, 2019; available ahead of print Nov 13, 2019.

Address for reprints: John W. C. Entwistle, MD, PhD, 1025 Walnut St, Suite 607, College Building, Philadelphia, PA 19107 (E-mail: john.entwistle@jefferson.edu).

J Thorac Cardiovasc Surg 2021;161:137-8

$0022-5223 / \$ 36.00$

Copyright (c) 2019 by The American Association for Thoracic Surgery

https://doi.org/10.1016/j.jtcvs.2019.10.142
}

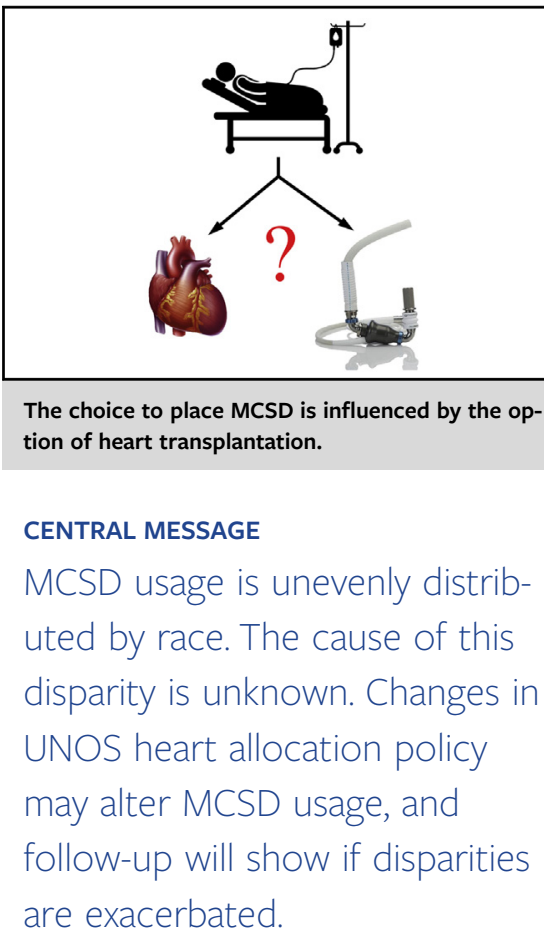

It is interesting that Bourque and coauthors ${ }^{1}$ chose to focus on UNOS regions, given the recent changes in heart allocation policies that remove "region" from the allocation system. In addition, new status levels were added to base allocation more on the severity of patient illness and less on wait list time. The older allocation system indirectly promoted the use of MCSD, because long wait times in the most urgent status levels necessitated durable MCSD placement in many patients with anticipated long wait times. As the new donor organ allocation policy replaces regional boundaries and allows more discrimination in patient urgency, it will be interesting to see whether MCSD usage rates change as a result and whether there are any changes in access to transplantation by race.

Because MCSD and transplantation are "competing" therapies, areas with lower organ availability may have higher rates of MCSD placement. Although the study of Bourque and coauthors ${ }^{1}$ focuses on UNOS regions for better granularity, data on organ availability are not presented, so we are not able to determine whether the regional differences in MCSD usage rates are related to donor availability. This could be an area of future study.

More granularity in data will likely allow modern computation-based research methodology, such as machine learning, to examine and analyze data by minority subgroups and by zip code. Such data exist on a vast number of topics, 
from financial disparity to climate change, ${ }^{5}$ and they could be leveraged in better understanding the nature of disparities.

Finally, we should not forget existing sex bias when providing advanced heart failure therapies. Women are older and sicker when they undergo coronary artery bypass grafting, and they receive far fewer heart transplants than men, ${ }^{6}$ despite equal incidences of cardiovascular disease and heart failure.

\section{References}

1. Bourque JL, Liang Q, Pagani FD, Zhang M, Aaronson KD, Kormos RL, et al; Michigan Congestive Heart Failure Investigators (MiCHF). Durable mechanical circulatory support device use in the United States by geographic region and minority status. J Thorac Cardiovasc Surg. 2021; 161:123-33.e13.

2. Sharma A, Colvin-Adams M, Yancy CW. Heart failure in African Americans: disparities can be overcome. Cleve Clin J Med. 2014;81:301-11.

3. Higgins RS, Fishman JA. Disparities in solid organ transplantation for ethnic minorities: facts and solutions. Am J Transplant. 2006;6:2556-62.

4. Williams DR, Wyatt R. Racial bias in health care and health: challenges and opportunities. JAMA. 2015;314:555-6.

5. Anderson M, McMinn S. As rising heat bakes U.S. cities, the poor often feel it most. NPR.org. Available at: https://www.npr.org/2019/09/03/754044732/asrising-heat-bakes-u-s-cities-the-poor-often-feel-it-most. Accessed October 15, 2019.

6. Beery TA. Gender bias in the diagnosis and treatment of coronary artery disease. Heart Lung. 1995;24:427-35. 